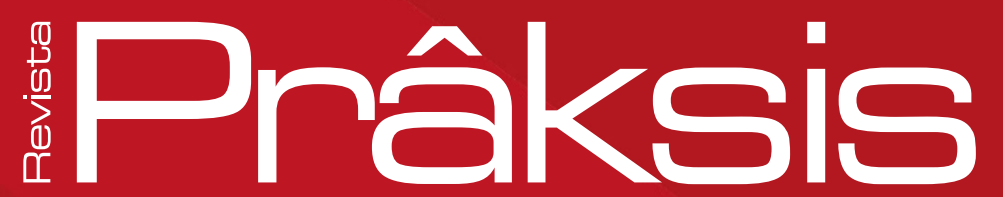

p-ISSN: 1807-1112

e-ISSN: 2448-1939

Recebido em: 01 de novembro de 2018

Aprovado em: 22 de março de 2019

Sistema de Avaliação: Double Blind Review

RPR |a. 16 | n. 2 | p. 301-314 | mai./ago. 2019

DOI: https://doi.org/10.25112/rpr.v2i0.1773

DESINSTITUCIONALIZAÇÃo PSIQUIÁTRICA: PRODUÇÃOO CULTURAL NA DIVERSIDADE

\title{
DESINSTITUCIONALIZAÇÃO PSIQUIÁTRICA: PRODUÇÃO CULTURAL NA DIVERSIDADE
}

Thomas Josué Silva

Doutor em Antropologia Social pela Universidade de Barcelona (Barcelona/Espanha). Professor da Universidade Federal do Pampa (Bagé/Brasil).

Email: thomasjosuesilva@gmail.com. 
Autêntica, 2001.

\section{RESUMO}

O artigo centra-se sobre a produção cultural e estética de usuários de saúde mental em contextos psicossociais e sua relação com a Reforma Psiquiátrica no Brasil. Trata-se de uma etnografia realizada na cidade de Novo Hamburgo que estuda a relação da criação visual e o sofrimento mental, e sua contribuição crítica para a pesquisa etnográfica em saúde mental e da arte na diversidade.

\section{ABSTRACT}

The article focuses on the cultural and aesthetic production of mental health users in psychosocial contexts and your relationship with the Psychiatric Reform in Brasil. This is an ethnography in Novo Hamburgo who studies the relationship of visual creation and mental suffering and your critical contribution to the ethnographic research in mental health and art in diversity. 


\section{INTRODUÇÃO}

No novo contexto da Reforma Psiquiátrica, assistimos à construção de novos territórios de atenção à saúde mental, com diferentes modalidades e propostas no Brasil e no exterior. No Brasil, vislumbramos a conquista da Lei 10216/01, que representou um grande avanço dos direitos civis e criou novas formas de encaminhamentos para a atenção à saúde mental. A referida lei propõe, por exemplo, o desmantelamento damanutenção dos espaçosasilares, os quais, durante décadas, assolarama cultura assistencial, centrados no modelo manicomial embasado na exclusão e na desapropriação da identidade social e da subjetividade da pessoa em sofrimento mental.

Nesse processo de consolidação da Lei 10.216/01, vêm se delineando propostas e o fortalecimento da superação do modelo hospitalocêntrico de atenção em saúde mental, exigindo o desenho da melhoria dos Centros de Atenção Psicossocial (Caps), residências terapêuticas, oficinas de trabalho e renda, entre outras tantas formas de promoção e cuidado à saúde mental.

Contudo, mesmo com esse grande avanço das Políticas Públicas de Atençãoà Saúde Mental, garantindo os direitos de cidadania às pessoas em sofrimento mental e a consolidação de novos territórios de atenção, ainda convivemos com contradições, lutas por saberes-poderes, reprodução de modelos clínicos tradicionais, com pouca interlocução com as demandas comunitárias. Convivemos também com a busca da reiteração dos "lugares" fixos, com pouca disposição de dialogar e de abertura para outros campos do saber que não os tradicionalmente ligados ao campo psi. Essa reflexão se aproxima da discussão trazida por Bourdieu (1990), reprodução-produção de saberes-poderes aliados a formas de manutenção de crenças e regras de um campo determinado, a doxa, que estrutura hegemonias de saberes.

Dessa forma, seria uma ilusão, e até ingenuidade, pensar que o problema da Reforma Psiquiátrica seria uma simples reforma técnico-administrativa de setor ou a criação de novos lugares extrahospitalares. Como lembra Thomas Szasz (1994, p. 295), mesmo com os novos dispositivos assistenciais fora do âmbito manicomial, podemos correr o risco de transformar esses novos territórios em lugares nocivos; pois estão subordinados a racionalizações burocrático-administrativas que não respondem substancialmente à complexidade que a Reforma Psiquiátrica instaura e gera no contexto da saúde mental contemporânea. Szasz se refere a esse fenômeno como a "futilidade da Reforma Psiquiátrica".

A partir das ideias de Szasz podemos pensar sobre a Reforma para além de uma simples questão técnico-administrativa, sobretudo porque ela instaura uma axiologia acerca da alteridade e sua extensão na sociedade mais ampla. Portanto, o que marca a tensão desse debate é a busca sempre revigorada, sempre ressemantizada do "lugar" que esses "diferentes" ocupam no contexto da sociedade capitalista. Assim, o que se coloca, indiscutivelmente, é a luta permanente da mudança de mentalidade que 
estabeleça uma nova relação entre aquele que sofre e aquele que cuida, entre a sociedade e a doença mental, na busca de novas formas de conhecimentos e de ações transformadoras. Como reflete Franco Basaglia (1982, p. 47), "o que deve transformar-se para poder transformar as instituições e os serviços psiquiátricos (como por outra parte todas as instituições sociais) é a relação entre cidadão e sociedade, na qual se insere a relação entre saúde e doença".

Diante dessa afirmativa, pensar sobre a Reforma Psiquiátrica, hoje, requer uma atitude de valor calcada na tentativa de promover, em conjunto com a sociedade mais ampla, uma mudança de mentalidade, superando o reducionismo de um pensamento reformista que não considera as complexidades socioculturais que estão em jogo na relação dialética entre loucura e sociedade; entre instituições e usuários; entre usuários e contexto sociais específicos. Isso do mesmo modo que entre ciência e novas práticas terapêuticas que vislumbrem outros horizontes interdisciplinares conjuntamente com a produção cultural contemporânea, que desemboca no enfrentamento de novas políticas de atenção e de promoção em saúde mental na sociedade contemporânea, privilegiando, assim, outros campos do saber, entre os quais as artes e as ciências humanas e sociais. Dessa forma, descortina-se a polissemia da experiência dos sujeitos com o sofrimento mental e sua relação com a cultura e a sociedade.

Tais premissas, dentro de uma filiação da Antropologia e Saúde (GOOD, 1994; TAUSSIG, 1995), colocam em questão o determinismo biomédico, que também migrou para o campo da saúde mental, centrando-se em uma visão unidimensional focalizada exclusivamente na perspectiva cura-enfermidade, desconsiderando os contextos socioculturais e as próprias experiências subjetivas dos sujeitos e dos grupos sociais com o fenômeno doença e saúde, e também a do sofrimento e seus significados.

O sofrimento psíquico, e também mente e contexto, já não pode mais ser analisado separadamente a partir de uma perspectiva cartesiana positivista, como entidades separadas uma das outras. Sem dúvida, o sujeito que sofre vive o sofrer no social, e o social vive no sujeito que sofre, no mesmo sentido que a dimensão corporal está no cultural e o cultural está no corporal. 0 antropólogo Geertz (2001, p. 181), ao refletir sobre o fenômeno complexo das relações entre corpo, mente e cultura, diz:

nossa mente não se encontra em nosso corpo, mas no mundo. E, quanto ao mundo, ele não está em nosso cérebro, nosso corpo ou nossa mente: estes é que, junto com os deuses, os verbos, as pedras e a política, estão nele.

Nessa direção, enfrentamos desafios de novas estratégicas teórico-metodológicas para lidar com essas dimensões que envolvem a mudança do modelo assistencial em saúde mental, e as atuais ameaças governamentais com a política de desinstitucionalização da saúde mental no Brasil, e também da própria formação acadêmica e científica em nosso meio. Essa nova formação se faz absolutamente necessária 
para enfrentar as complexidades que envolvem o cuidar e o pensar sobre saúde mental e as instituições hoje. Nesse sentido, ao discutir sobre o tema Freitas (1998, p. 93-106) adverte:

Que instrumentos e quais os recursos necessários para afrontar os desafios de recuperação da relação entre o valor de saúde, o valor de vida e a crise enquanto tal? Trata-se, portanto, de componentes de um novo paradigma ainda ausente nos nossos meios acadêmicos e profissionais.

O novo paradigma da atenção psicossocial suscitado pela desinstitucionalização psiquiátrica evoca uma crítica à relação de poder imposta pela instituição psiquiátrica e seus desdobramentos, entre os quais a medicalização social e seus efeitos na vida cotidiana dos sujeitos que sofrem e da necessidade de novas práticas e saberes para enfrentar o problema.

Dessa forma, todos nós somos chamados a pensar sobre saúde mental para além das soluções reducionistas defendidas pelos arranjos burocrático-administrativos das políticas de assistência ou pelo modelo liberal-assistencial trazido pelo advento das instituições modernas. Todavia, na contemporaneidade, o campo da saúde mental fez ascender novos desafios políticos e científicos na busca de práticas transformadoras que devam valorizar as experiências locais sem pretender importar modelos exógenos, mas que contemplem o valor das trocas de saberes e de cooperações microssociais nos contextos onde os próprios conflitos emergem. Isto é, que contemplem a construção de novos sentidos existenciais baseados em ações coletivas de melhoria da sociabilidade e da relação com as diferenças, em que a diversidade possa afirmar-se na construção de espaços de vida e de liberdade de expressão.

Na atualidade, a Reforma Psiquiátrica no Brasil emerge desses princípios, dando destaque a novas formas e estratégias sociais de enfrentar o problema (AMARANTE, 2008). A incorporação de novas políticas que garantam a expressão da diversidade no campo psicossocial foi garantida na discussão iniciada pelo Projeto Loucos pela Diversidade - da diversidade da loucura à identidade da cultura", liderada pelo pesquisador Paulo Amarante (2008), com a colaboração de diferentes intelectuais e artistas de diferentes setores da produção cultural.

Assim, o campo da produção cultural é convocado a atuar diretamente na esfera da atenção psicossocial, apontando para novos horizontes da polissemia de narrativas estéticas que precisam ser encaradas como verdadeiras formas de um devircultural que enriquece o debate da relação do sofrimento psíquico e sociedade.

Nossa experiência com os processos e manifestações culturais na diversidade psicossocial vem elucidando a ampliação da relação entre produção cultural e saúde mental, o que vem se desdobrando há 
mais de 20 anos em nossa inserção no campo, na condição de produtores culturais e pesquisadores. Essa jornada iniciou nos trabalhos inaugurais dos anos de 1990, quando a Reforma Psiquiátrica no Brasil dava seus primeiros passos em direção a uma política de transformação do modelo assistencial e cultural da atenção em saúde mental até então vigente. Dentro desse contexto surgiu o Atelier de Expressão (ATE), vinculado, institucionalmente, ao Serviço de Saúde Mental do Município de Novo Hamburgo, que oferecia, semanalmente, atividades de artes visuais e oficinas de sensibilização artística aos usuários daquele serviço em trabalhos de grupo ou individuais, respeitando a expressão de cada sujeito e sua apropriação dos materiais plásticos sem a intenção de ensinar ou corrigir, pois não se tratava de uma escola de artes, mas de uma oficina de desenvolvimento integral da expressão dentro do princípio de sociabilidade, de trocas afetivas e de memórias biográficas oriundas das produções artísticas tanto grupais quanto individuais. Esse projeto de oficinas de expressão artística era realizado nas dependências do Atelier Livre da Secretaria da Educação e Cultura de Novo Hamburgo, em conjunto com um amplo público de estudantes de artes, artistas e docentes da comunidade.

O ATE foi o palco de nosso trabalho, na condição de produtores culturais e de pesquisadores sociais inseridos em um projeto de socialização dos meios da linguagem artística na diversidade. Nele também desenvolvemos nossa reflexão teórica ao vislumbrar o local como potência afirmativa de um trabalho inovador e profícuo da desinstitucionalização psiquiátrica em suas mais ramificadas possibilidades de produção cultural e de promoção da saúde mental dos grupos sociais vulneráveis.

\section{ATELIER DE EXPRESSÃO DE NOVO HAMBURGO: UMA EXPERIÊNCIA ESTÉTICA NO CAMPO PSICOSSOCIAL}

Neste tópico apresentamos um breve relato etnográfico que evidencia algumas das questões anteriormente tratadas, mesmo que essa experiência esteja sendo rememorada em seu contexto de práticas. Alude-se, assim, a uma etnografia revisitada, pois como processo histórico, esta narrativa de memória retoma temas atuais emergentes no cenário obscuro de ameaças aos avanços das políticas de atenção psicossocial que foram conquistadas no período pós-ditadura militar em pleno processo de democratização do país.

\section{DISCUSSÃO ETNOGRÁFICA}

Aborda-se, aqui, a experiência local do Atelier de Expressão de Novo Hamburgo (ATE), nos anos de 1990 a 1994, na cidade de Novo Hamburgo, RS, em pleno processo de lutas e de conquistas da Reforma Psiquiátrica Brasileira, influenciada pelos ideários da Reforma Italiana liderada pelo italiano 
Franco Basaglia, nos anos 1970. Essa experiência possibilitou, através da contribuição dos processos e manifestações culturais dos usuários do ATE (Atelier de Expressão do Serviço de Saúde Mental de Novo Hamburgo, à época) vetor metodológico através da criação visual associada às narrativas verbais de nossos interlocutores uma abordagem etnográfica, nesse momento revisitada.

\section{Figura 1 - Cena dos usuários do ATE, em um dia de sessão de pintura}

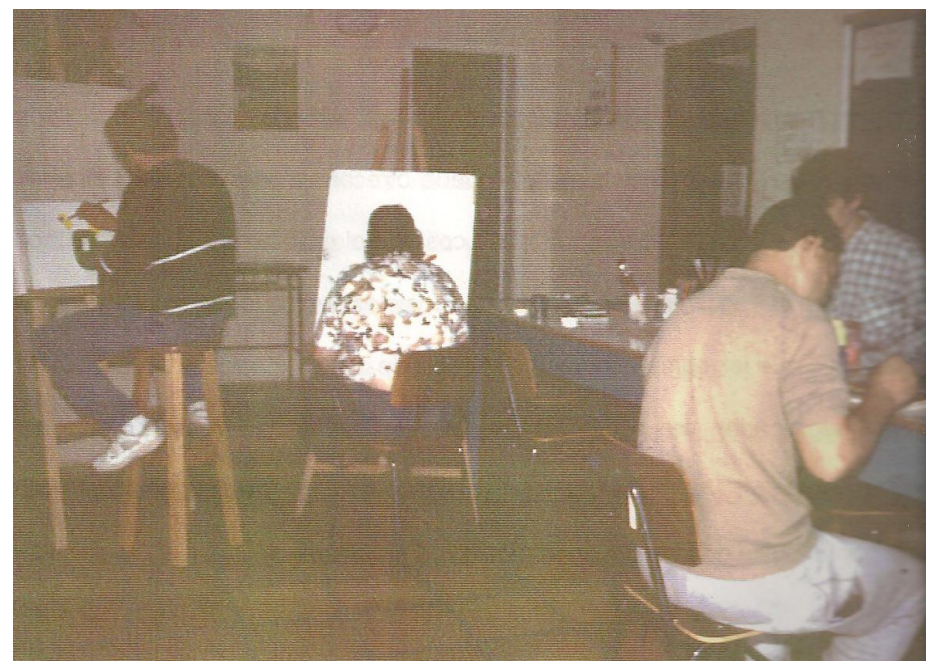

Fonte: Fotos do acervo do autor (2018)

Essa experiência singular com a dimensão da criação plástica e com as narrativas biográficas de usuários, em um território que não era marcado pelo tratamento ou reabilitação psicossocial, possibilitou encontros significativos, nos quais a doença mental pôde ser relativizada e redimensionada em outro sentido que não aquele em que o usuário é apenas considerado doente alguém em tratamento. Todavia, através da apropriação de recursos da criação visual, o usuário pôde dar visibilidade a contextos representacionais de sua experiência subjetiva com o sofrimento mental, pôde dialogar com criações visuais e realidade psicossocial concreta, propiciando novos arranjos narrativos entre mundo interno e mundo social.

A convivência social e o clima de trocas de experiências de vida entre os usuários durante as atividades de pintura, modelagem ou desenho, permitiram o que poderíamos denominar de um verdadeiro território de escutas sociais habitado por vozes que tiveram suas histórias de vida marcadas por fortes processos de estigmatização e exclusão. Mas naquele momento de convivência social no ATE podiam estabelecer 
trocas, vivências, diálogos, cooperações e expressar seus anseios, suas preocupações reais. Essa questão é evidenciada na fala de uma usuária:

Eu aqui, no ATE, falo de minhas coisas, de minha história de vida. Pinto, desenho, encontro meus companheiros e tomo chá com eles. Eu venho aqui porque me sinto bem aqui.

Outro usuário do ATE falou sobre sua preocupação em voltar ao mundo do trabalho:

Será que aqui eu trabalhando com pintura e desenho, eu vou voltar a trabalhar um dia?.

E outro ainda narrou a importância de seu trabalho com a criação plástica, como algo que lhe permitiu uma nova possibilidade de falar sobre sua vida e sobre sua experiência com a doença mental:

Eu aqui no ATE desenho. $O$ desenho é a restauração do paraíso para mim. 0 desenho me ajuda. $O$ desenho é melhor que os remédio.

uma das usuárias, ao pintar uma imagem que representava sua vida na infância, disse:

Aqui eu me sinto bem... me lembro das coisas que vivi na escola, na infância. Minha vida antes daqui.

Percebemos, nas narrativas dos interlocutores, a importância dos processos de criação na construção de uma discursividade voltada a aspectos de reabilitação psicossocial de ressocialização e ao contexto do sofrimento mental, e também da própria atividade de contato com a dimensão das artes visuais um novo vetor de produção de subjetividade e de memórias de vida. 


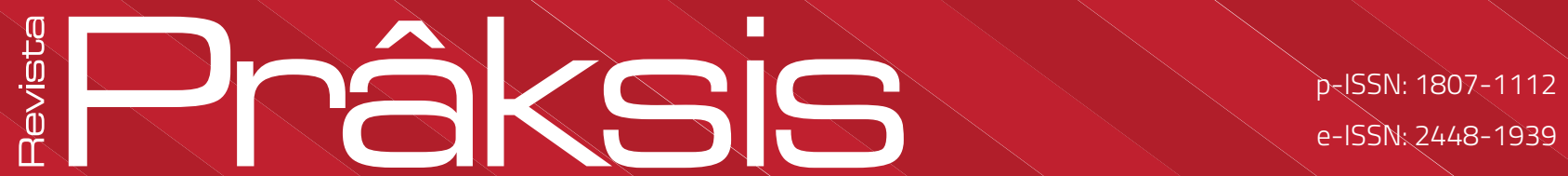

\section{AS CRIAÇÕES VISUAIS DOS INTERLOCUTORES: PROCESSOS E MANIFESTAÇÕES CULTURAIS PARA ALÉM DA DOENÇA MENTAL}

Figura 2 - Pintura realizada por uma das usuárias

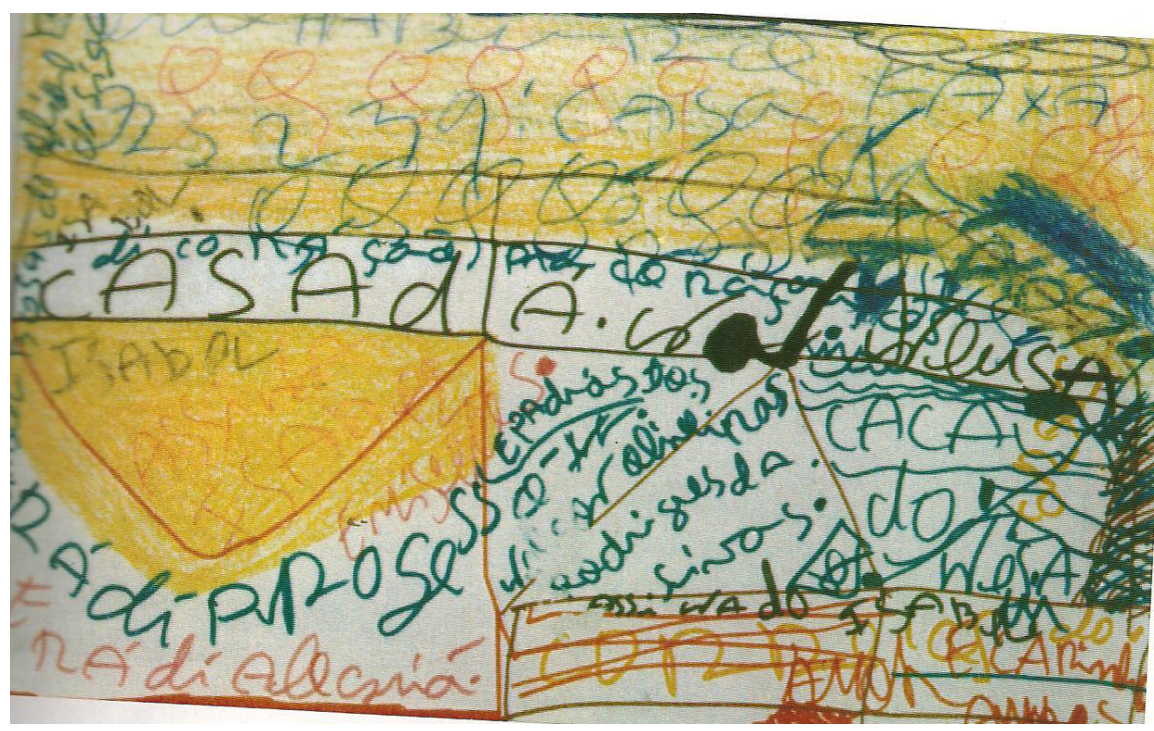

Fonte: Fotos do acervo do autor (2018)

Essa criação visual de uma das usuárias do ATE narrava sua biografia e sua relação com a escola primária através de letrismos, suas dificuldades de adaptação a um contexto hostil e discriminatório que foi sua experiência com a escola formal. Não chegou a concluir seus estudos primários e foi afastada da escola, à época, por apresentar um comportamento não adaptável ao ambiente escolar, segundo depoimento da mãe da interlocutora, durante o processo de nossa interação etnográfica. 


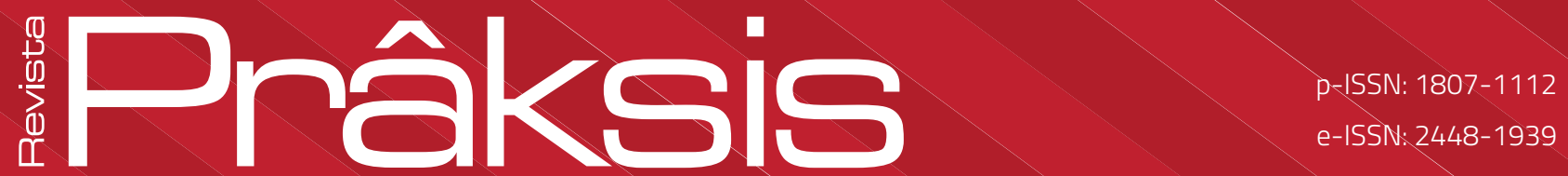

Figura 3 - Representação da escola primária de uma usuária

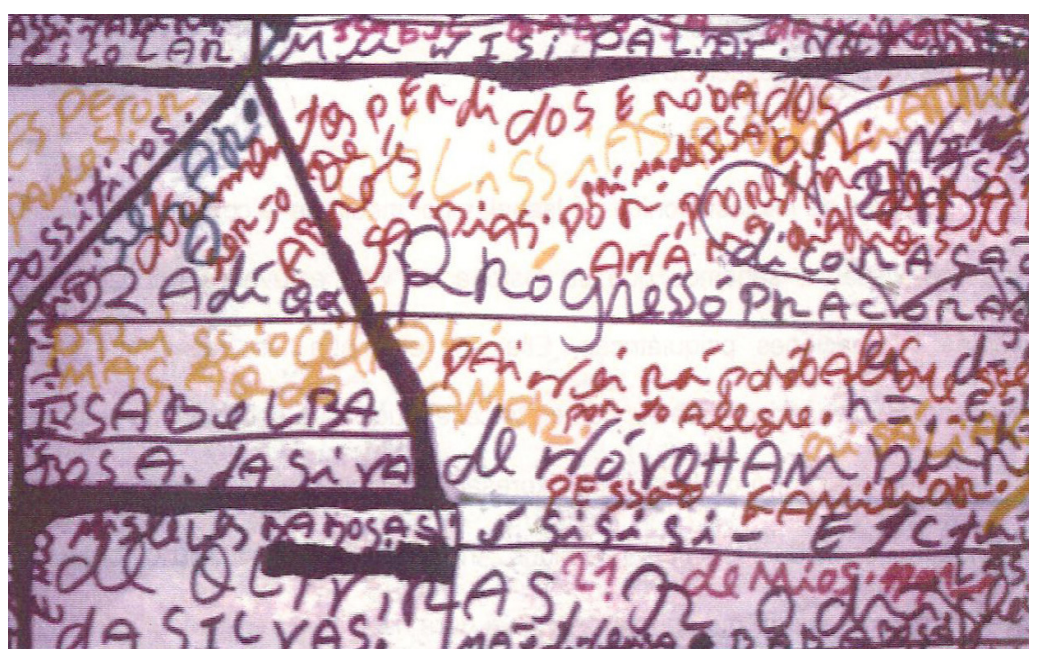

Fonte: Fotos do acervo do autor (2018)

Outra composição visual foi realizada por uma interlocutora que evidenciou a representação da escola primária e de suas primeiras vivências com o mundo escolar. Nessa imagem, ela relatou as memórias das aulas de alfabetização e da vontade que ela, hoje, adulta, manifestava o desejo de aprender a ler e a escrever para contar sua história de vida.

Figura 4 - Criação visual de uma usuária - biografia

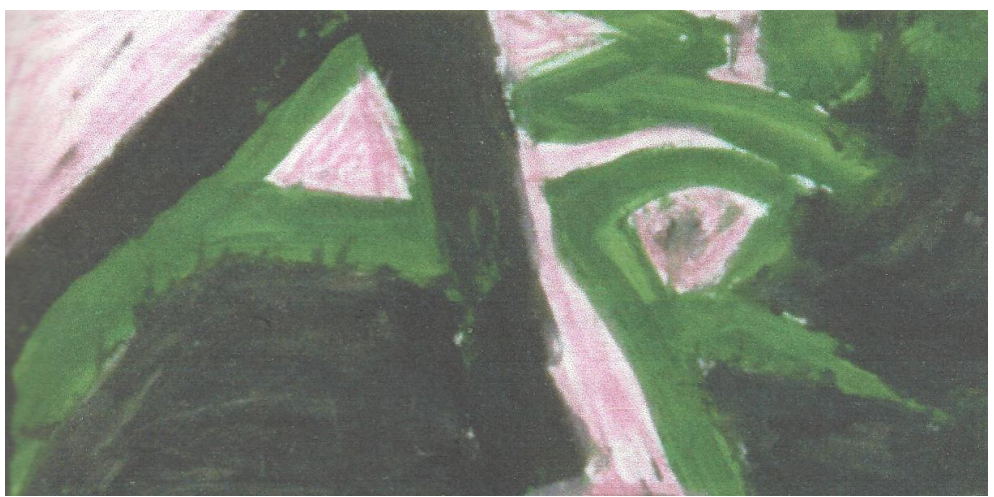

Fonte: Fotos do acervo do autor (2018) 
Nessa criação visual, a interlocutora demonstrou sua tenacidade em tentar escrever palavras que constituíssem narrativa de sua biografia. Ela disse: "Eu tentei aqui escrever algo ...como eu vou dizer...da minha história".

Figura 5 - Criação visual de um usuário - memórias da infância

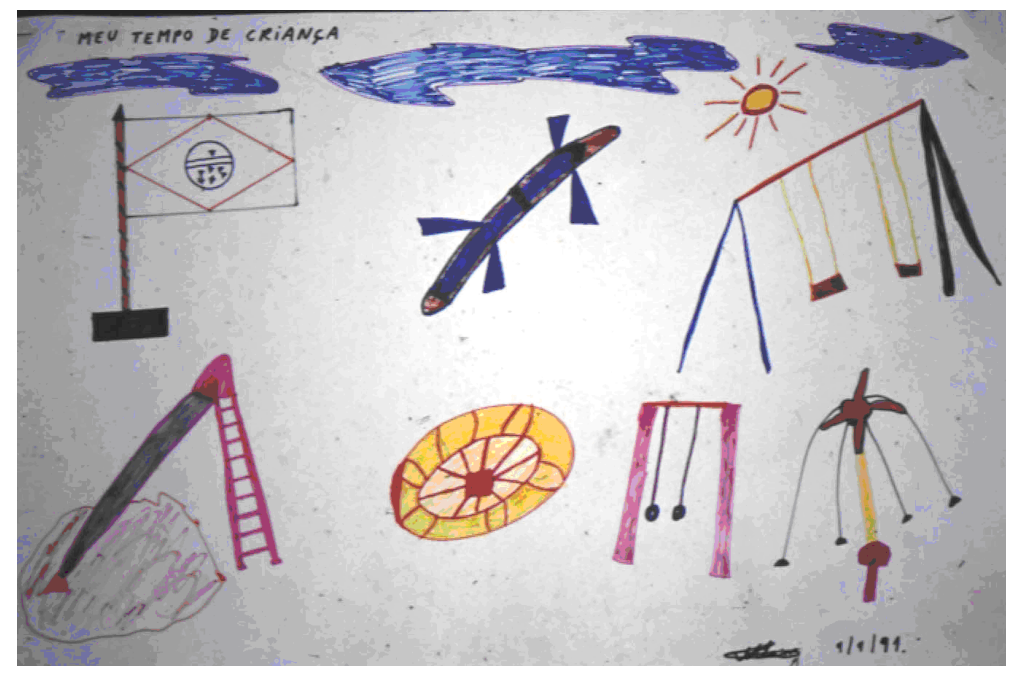

Fonte: Fotos do acervo do autor (2018)

Observando a produção visual de outro interlocutor de nossa etnografia, percebemos também a retomada do tema das memórias de vida, da infância. Nessa clara representação de uma praça de brinquedos de crianças, o interlocutor relata suas brincadeiras de menino com outras crianças, seus momentos de lazer fora da escola. Nesse contexto representacional, através desse desenho, ele apresenta uma biografia carregada de lembranças de um tempo que "não volta mais", segundo suas próprias palavras. 
Figura 6 - Representação da casa paterna

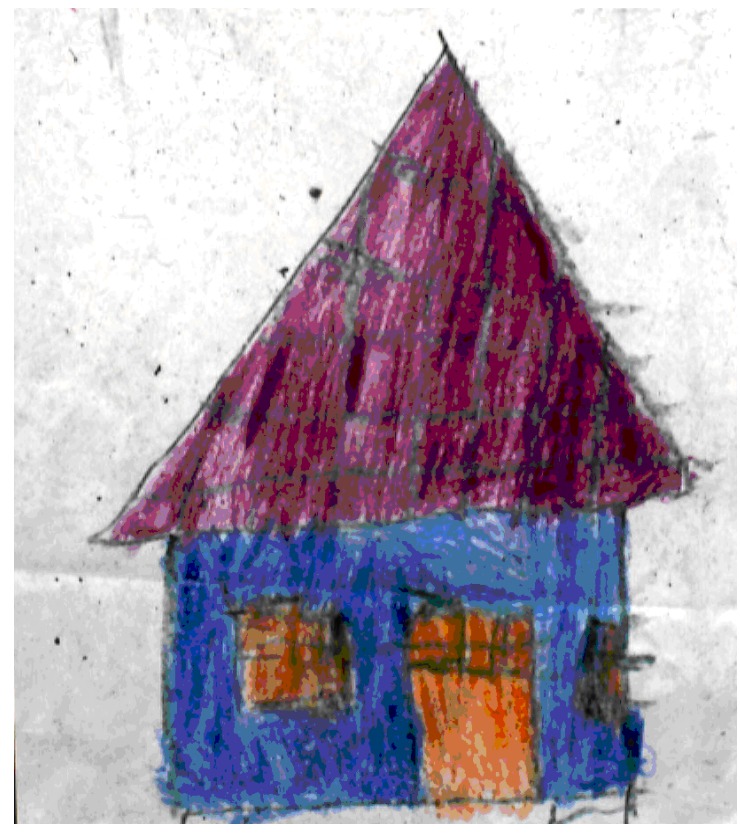

Fonte: Fotos do acervo do autor (2018)

A imagem da Figura 6, elaborada por outro usuário, que chegou ao ATE após sua saída de uma internação hospitalar superior a oito meses, foi intitulada por ele mesmo de a "casa paterna", durante o processo de criação. Representava sua angústia de voltar para a casa de seu pai, sua única referência familiar, após sua internação asilar, pois sua relação com o pai era "ruim"e não conseguia conviver com ele. $O$ pai demonstrava demasiada agressividade e não entendia os desdobramentos de sua doença. Suas narrativas visuais eram marcadas por conteúdos de medo e pânico por ter que voltar a casa paterna, sendo que o destino social desse interlocutor revelava uma dupla dramaticidade de lugar, de pertencimento: ficar internado como doente em um hospital ou se submeter às agressões do pai. Por sua vez, o pai relatou: "o que vou fazer agora com ele de volta... não sei o que fazer... ele não trabalha não faz nada... tenho que sustentar todos e mais este."

Nesses breves relatos fica evidente que a questão vai além do psicopatológico. Essas narrativas e representações visuais dos interlocutores do ATE nos possibilitaram dar visibilidade a conteúdos subjetivos e biográficos, os quais contribuíram para compreender a relação intrínseca entre sofrimento psíquico e sua interface com os processos de criação e de produção cultural na diversidade. 
Portanto, mesmo que tenhamos feito, aqui, um breve relato sobre essa experiência, o ATE representou um território onde as relações sociais puderam ser consideradas para além do circuito patológico. Estabelecemos arranjos de convivência social mediados pela criação plástica, pela construção de narrativas iconográficas, as quais permitiram reflexões sobre a complexidade da atenção psicossocial, da necessidade da promoção de novos espaços culturais e sociais, em que a voz dos usuários pudesse ser escutada sob outra ordem. Não somente da ordem do nosológico, mas do social, do subjetivo e do cultural; da construção da pessoa que sofre para além do estigma.

Acreditamos que experiências semelhantes a essa vivida no ATE podem revelar outras possibilidades de promover a saúde mental. Ainda mais se lançarmos sobre elas um olhar interdisciplinar que nos ajude a construir conhecimentos baseados no diálogo entre os atores sociais envolvidos na diversidade dos contextos culturais; poderemos, assim, ultrapassar a própria cronicidade dos modelos de atenção ainda vigentes dentro dos Caps, e buscar, juntamente com outros segmentos sociais, com outros atores e outros saberes, a construção de uma Reforma viva e criativa em constante transformação.

\section{CONSIDERAÇÕES FINAIS}

Ao finalizar este artigo, acreditamos que as pesquisas em Ciências Humanas e Sociais, no contexto da desinstitucionalização psiquiátrica, vivenciadas no ATE, contribuem, de forma qualitativa e substancial, para a construção crítica, abrindo espaço para novas leituras interdisciplinares acerca das relações entre sofrimento mental e sociedade. Também provocam nossa reflexão sobre outras vias de produção de saúde mental e produção cultural no bojo da diversidade social e cultural.

O que a desinstitucionalização psiquiátrica exige é uma profunda reflexão acerca do lugar que a experiência da saúde-doença mental ocupa no contexto da globalização capitalista, e quais os recursos que disponibilizamos para enfrentar as complexidades que a atenção em saúde mental está nos exigindo diante dos novos conflitos e demandas socioculturais observadas em nossa contemporaneidade.

A urgência do valor de experiências locais inovadoras podem nos ajudar a vislumbrar a diversidade dos modos e dos múltiplos rostos da desinstitucionalização psiquiátrica em nossa atualidade, que é construída cotidianamente no enfrentamento de conflitos, na organização social, na dialética entre formação acadêmica e realidade social, na constante busca por recursos para a humanização da atenção. E também no compromisso com novas abordagens teórico-metodológicas qualitativas que nos possibilitem a constituição de reflexões e ações para um projeto de uma Reforma menos técnicoburocrática, dando lugar a uma Reforma em constante movimento e (re)construção, correspondendo a uma dialética necessária entre realidades socioculturais e saúde mental dos grupos sociais envolvidos. 


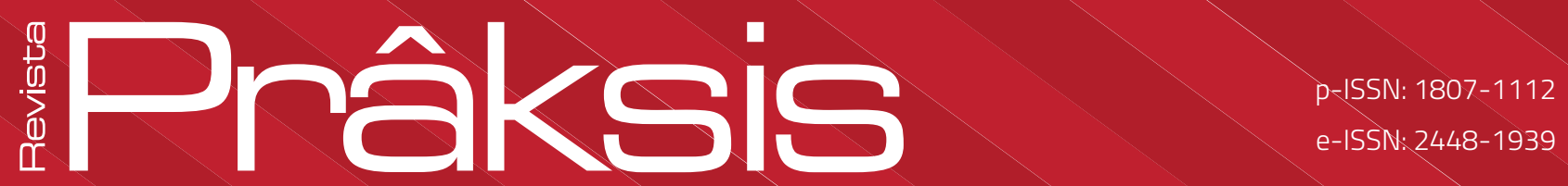

O ATE foi um território de produção de memórias promovida por narrativas ético-estéticas que ajudaram a construir espaço de vida, e que demonstrou que os processos de criação de nossos interlocutores foram substancialmente importantes na consolidação de uma crítica ao determinismo nosológico e ao imperativo psiquiátrico. Suas criações formaram um caleidoscópio de devires que nos convidam até hoje a travar uma luta constante contra os estigmas e as lógica excludentes que pairam sobre os processos e produções culturais vividas na diversidade.

\section{REFERÊNCIAS}

AMARANTE, Paulo. Relatório Final da Oficina Nacional de Indicações de Políticas Públicas Culturais para pessoas em sofrimento mental e em situações de risco social. Rio de Janeiro: Fiocruz/ Laps, 2008.

BASAGLIA, F. Utopía de la realidad y realidad de la utopía. In: FORTI, Laura (Org.). La otra locura. Barcelona: Tusquets, 1982.

BOURDIEU, P. Coisas ditas. São Paulo: Brasiliense, 1990.

FREITAS, F.F.P. Subsídios para mudança do modelo de assistência psiquiátrica. Cad. Saúde Pública, Rio de Janeiro, v. 14, n. 1, p. 93-106, jan./mar, 1998.

GEERTZ, C. Nova luz sobre a antropologia. Rio de Janeiro: Jorge Zahar, 2001.

GOOD, B.J. Medice, rationality, and experience: an anthropological perspective. Cambridge University. Press, Inglaterra, 1994.

LEI 10216/01, de 6 de abril de 2001. Dispõe sobre a proteção e os direitos das pessoas portadoras de transtornos mentais e redireciona o modelo assistencial em saúde mental. Diário Oficial da União, Brasília, DF, 9 abr. 2001. Seção 1)

SZASZ, T. Cruel compaixão. Campinas: Papirus, 1994.

TAUSSIG, M. Un gigante en convulsiones. Barcelona: Gedisa, 1995. 